Article

\title{
Advances and Applications of Ion Torrent Personal Genome Machine in Cutaneous Squamous Cell Carcinoma Reveal Novel Gene Mutations
}

\author{
Yu-Ping Hsiao ${ }^{1,2}$, Chun-Te Lu ${ }^{1,3}$, Ju Chang-Chien ${ }^{4,5}$, Wan-Ru Chao ${ }^{1,6}$ and Jiann-Jou Yang ${ }^{4,7, *}$ \\ 1 Institute of Medicine, School of Medicine, Chung Shan Medical University, Taichung 402, Taiwan; \\ missyuping@gmail.com (Y.-P.H.); ctlu119@vghtc.gov.tw (C.-T.L.); littleuni@hotmail.com (W.-R.C.) \\ 2 Department of Dermatology, Chung Shan Medical University Hospital, Taichung 402, Taiwan \\ 3 Division of Plastic Surgery, Taichung Veterans General Hospital, Taichung 407, Taiwan \\ 4 Department of Biomedical Sciences, Chung Shan Medical University, Taichung 402, Taiwan; \\ swan1204@hotmail.com \\ 5 Institute of Microbiology and Immunology, College of Medicine, Chung Shan Medical University, \\ Taichung 402, Taiwan \\ 6 Department of Pathology, Chung Shan Medical University Hospital, Taichung 402, Taiwan \\ 7 Department of Medical Sciences, Chung Shan Medical University Hospital, Taichung 402, Taiwan \\ * Correspondence: jiannjou@csmu.edu.tw; Tel.: +886-4-2473-0022 (ext. 12372)
}

Academic Editor: Subbu S. Venkatraman

Received: 27 March 2016; Accepted: 8 June 2016; Published: 14 June 2016

\begin{abstract}
The Ion Torrent Personal Genome Machine (Ion PGM) is a semiconductor-based sequencing technology that is high quality, scalable, and economic. Its applications include genomic sequencing, drug resistance testing, microbial characterization, and targeted sequencing in cancer studies. However, little is known about the application of Ion PGM in cutaneous squamous cell carcinoma ( $\mathrm{CSCC}$ ). We therefore investigated the utility and validity of Ion PGM in CSCC and also gained a better understanding of the underlying molecular biology of CSCC. We detected novel gene mutations (KDR, FGFR2, and EGFR) in two cSCC patients. Moreover, we validated these mutations by pyrosequencing and Sanger sequencing. Our results indicated that the mutation screen using Ion PGM is consistent with traditional sequencing methods. Notably, these identified mutations were present at significantly higher rates in high-risk CSCC. Our results demonstrate a method to detect targetable genes in high-risk CSCC, and suggest that Ion PGM may enable therapeutic decision-making and future potential targets for personalized therapies in CSCC.
\end{abstract}

Keywords: ion torrent personal genome machine; next generation sequencing technology; squamous cell carcinoma

\section{Introduction}

Cutaneous squamous cell carcinoma (cSCC) derived from keratinocytes of the skin can be locally invasive or distantly metastatic [1-3]. cSCC is the leading fatal cause in non-melanoma skin cancers $[1,3,4]$ and the second most common skin cancer, accounting for $15 \%-25 \%$ of all cutaneous malignancies $[1,5,6]$. Approximately 250,000 cSCCs are diagnosed annually in the United States and the incidence is still increasing [1,7]. Mortality from CSCC is usually due to metastasis $[1,5,8]$ and the survival rate has not declined in decades [9]. Some hypotheses for the carcinogenesis of cSCC have been proposed [2,6,10], but the actual etiology and carcinogenesis of CSCC remains unclear [11,12].

cSCC represents a classic model of somatic mutation and a fundamentally genetic disease with highly individualized genetic etiology [13,14]. The Ion Torrent Personal Genome Machine (Ion PGM), a next generation sequencing technology, has revolutionized genetic and genomic research with the 
comprehensive analysis of genomes, transcriptomes and interactomes $[15,16]$. Based on semiconductor sequencing technology that detects electrical signals directly on a disposable chip, Ion PGM has the advantages of high accuracy, speed and affordability $[17,18]$. To date, little is known about the utilization of Ion PGM in CSCC. In this study, we investigated the mutational patterns of the key genes in cSCC by Ion PGM, pyrosequencing and Sanger sequencing.

\section{Results}

\subsection{Demographic Data}

We included 67 cSCC specimens from patients of ages ranging from 44 to 93 years (mean age: 73.9 years old) and of both sexes (female: 29 ; male: 38$)$. Of the 67 tumors, 51 (76.1\%) were from patients of advanced age, and $16(23.9 \%)$ were from patients below 65 years old. Forty-two (62.7\%) specimens came from sun-exposed sites and $25(37.3 \%)$ came from non-sun-exposed sites. Eighteen $(26.9 \%)$ of the specimens were larger than $2 \mathrm{~cm}$, and six $(9 \%)$ had deep invasion with Clark level IV. The ratios of histopathological grading were nine (13.4\%) well differentiated, $39(58.2 \%)$ moderately differentiated, and $19(28.4 \%)$ poorly differentiated. There were three $(4.5 \%)$ cases with distal metastasis and seven (10.4\%) with recurrence. We assigned risk according to the American Joint Committee on Cancer staging manual, 7th Edition (AJCC-7), with risk features including tumor diameter $2 \mathrm{~cm}$, Clark level IV, tumor thickness $>2 \mathrm{~mm}$, location on ear or non-hair-bearing (vermillion) lip, poorly differentiated histologic finding for the first time, and perineural invasion [1]. Thirty-seven (55.2\%) were designated as high-risk cSCCs, and 30 (44.8\%) were low risk (Table 1).

Table 1. Demographic and histopathological data of cutaneous squamous cell carcinoma patients.

\begin{tabular}{cccccc}
\hline Characteristics & No. of Patients & Percentage & Characteristics & No. of Patients & Percentage \\
\hline Age & - & - & Differentiation & - & - \\
$<65$ & 16 & 23.9 & Poor & 19 & 28.4 \\
$\geqq 65$ & 51 & 76.1 & Moderate & 39 & 58.2 \\
Sex & - & - & Well & 9 & 13.4 \\
Male & 38 & 56.7 & Recurrence & - & - \\
Female & 29 & 43.3 & No & 60 & 89.6 \\
Location & - & - & Yes & 7 & - \\
Face & 28 & 41.8 & Metastasis & - & 95.5 \\
Ear and lip & 14 & 20.9 & No & 64 & 4.5 \\
Others & 25 & 37.3 & Yes & 3 & - \\
Tumor size & - & - & Risk & - & 44.8 \\
$\leqslant 2$ cm & 49 & 73.1 & Low & 30 & 55.2 \\
$>2$ cm & 18 & 26.9 & High & 37 & - \\
Clark level & - & - & - & - & - \\
$<$ IV & 61 & 91.0 & - & - & - \\
$\geqq$ IV & 6 & 9.0 & - & - & \\
\hline
\end{tabular}

\subsection{Target Variants of High-Risk cSCC Using Ion Torrent Personal Genome Machine}

Among the high-risk CSCCs, two specimens were microdissected and analyzed for driver gene mutations using a panel covering 739 mutations in 46 cancer-related genes (Ion AmpliSeq Cancer Panel, Life Technologies, Carlsbad, CA, USA). In patient one, 14 different mutations were observed in 11 cancer-related genes. Among these mutations, seven were missense mutations and the rest were silent mutations (Table 2). In patient two, 14 different mutations were observed in 12 cancer-related genes. Among these mutations, seven were missense mutations and the rest were silent mutations (Table 3). Five of the seven missense mutations were found in both patients one and two: a KDR mutation (Chr. 4; g. 55972974 T > A); an EGFR mutation (Chr. 7; g. 55249110 G > A); two FGFR2 mutations (Chr. 10; g. $123274818 \mathrm{~T}>$ A and g. $123274819 \mathrm{~T}>$ C); and a HNF1A mutation (Chr. 12; g. 121432011G > C). Based on the above results, four target oncogenes (KDR, EGFR, FGFR2, 
and HNF1A) from the two high-risk cSCC patients were subsequently confirmed for the presence of missense gene mutations with pyrosequencing and Sanger sequencing.

Table 2. Target variants of high-risk cSCC no. 1 specimen.

\begin{tabular}{cllllcccccc}
\hline Chrom & Position & Gene Sym & Ploidy & Ref & Variant & VarFreq & Coverage Ref Cov & Var Cov & AA Mut \\
\hline chr4 & 1807894 & FGFR3 & Hom & G & A & 99.64 & 1652 & 6 & 1646 \\
chr4 & 55141055 & PDGFRA & Hom & A & G & 99.92 & 4967 & 1 & 4963 \\
chr4 & 55972974 & KDR & Hom & T & A & 99.87 & 3051 & 3 & 3047 & p.Q427H \\
chr5 & 112175770 & APC & Hom & G & A & 99.73 & 1472 & 4 & 1468 & - \\
chr7 & 55249063 & EGFR & Het & G & A & 44.12 & 102 & 57 & 45 & - \\
chr7 & 55249110 & EGFR & Het & G & A & 8.33 & 2160 & 1980 & 180 & p.R803Q \\
chr7 & 116339672 & MET & Het & C & T & 53.44 & 1106 & 514 & 591 & - \\
chr7 & 116340262 & MET & Het & A & G & 51.56 & 3305 & 1598 & 1704 & p.N375S \\
chr10 & 43613843 & RET & Het & G & T & 51.06 & 47 & 23 & 24 & - \\
chr10 & 123274818 & FGFR2 & Het & T & A & 5.37 & 3797 & 3582 & 204 & p.K367M \\
chr10 & 123274819 & FGFR2 & Het & T & C & 10.88 & 3905 & 3479 & 425 & p.K367E \\
chr11 & 108236046 & ATM & Het & C & G & 5.45 & 716 & 676 & 39 & - \\
chr12 & 121432011 & HNF1A & Het & G & C & 4.38 & 3450 & 3292 & 151 & p.G253A \\
chr14 & 105246407 & AKT1 & Het & G & A & 43.66 & 6439 & 3627 & 2811 & - \\
\hline
\end{tabular}

Table 3. Target variants of high-risk cSCC no. 2 specimen.

\begin{tabular}{ccccccccccc}
\hline Chrom & Position & Gene Sym & Ploidy & Ref & Variant & Var Freq & Coverage & Ref Cov & Var Cov & AA Mut \\
\hline chr3 & 178952190 & PIK3CA & Het & C & A & 7.42 & 1307 & 1209 & 97 & - \\
chr4 & 1807894 & FGFR3 & Hom & G & A & 99.67 & 1534 & 1 & 1529 \\
chr4 & 55141055 & PDGFRA & Hom & A & G & 99.91 & 5433 & 4 & 5428 & - \\
chr4 & 55152040 & PDGFRA & Het & C & T & 61.32 & 6981 & 2699 & 4281 & - \\
chr4 & 55972974 & KDR & Het & T & A & 52.74 & 2300 & 1085 & 1213 & p.Q427H \\
chr5 & 112175770 & APC & Hom & G & A & 99.24 & 1964 & 14 & 1949 & - \\
chr7 & 55249110 & EGFR & Het & G & A & 6.79 & 3227 & 3004 & 219 & p.R803Q \\
chr9 & 21971179 & CDKN2A & Het & G & A & 58.12 & 1194 & 499 & 694 & p.A60V \\
chr10 & 43613843 & RET & Het & G & T & 43.9 & 41 & 23 & 18 & - \\
chr10 & 123274818 & FGFR2 & Het & T & A & 5.94 & 4445 & 4169 & 264 & p.K367M \\
chr10 & 123274819 & FGFR2 & Het & T & C & 11.02 & 4536 & 4027 & 500 & p.K367E \\
chr11 & 108236046 & ATM & Het & C & G & 5.01 & 659 & 624 & 33 & - \\
chr12 & 121432011 & HNF1A & Het & G & C & 4.52 & 2743 & 2612 & 124 & p.G253A \\
chr13 & 48942722 & RB1 & Het & C & T & 8.91 & 404 & 368 & 36 & p.P370L \\
\hline
\end{tabular}

\subsection{Mutation Prevalence in cSCC According to Tumor Risk}

Target genes' missense mutations (KDR, EGFR, FGFR2 and HNF1A) were detected by PCR in 67 microdissected cSCC samples. We used pyrosequencing to detect EGFR g. $55249110 \mathrm{G}>\mathrm{A}$ and FGFR2 g. $123274818 \mathrm{~T}>\mathrm{A}$ mutations in $22(32.8 \%)$ and $28(41.8 \%)$ of the cSCC samples (Figure 1), respectively. Simultaneously, No FGFR2 g. 123274819 T > C mutant was found in this study by pyrosequencing. In addition, the KDR g. $55972974 \mathrm{~T}>\mathrm{A}$ mutant was validated by Sanger DNA sequencing (Figure 2). Our results indicated a mutation rate of $61.2 \%(41 / 67)$ in cSCC. Among 41 patients, 14 were homozygous $(14 / 41 ; 33.3 \%)$ and 27 were heterozygous mutations (27/41; $66.7 \%$ ), respectively. These results indicate that the mutation screen by Ion PGM is consistent with the traditional sequencing method. However, the FGFR2 g. $123274819 \mathrm{~T}>\mathrm{C}$ mutant was not detected by pyrosequencing, nor was the HNF1A mutation detected by pyrosequencing and Sanger sequencing. 
(a)

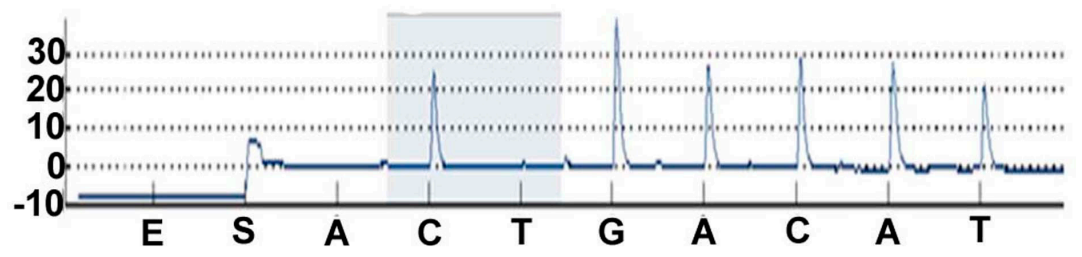

(b)

A: $96 \%$

$\mathrm{T}: \mathbf{4 \%}$

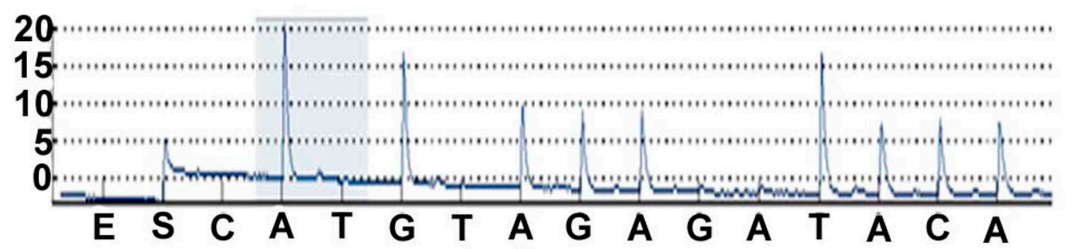

Figure 1. EGFR and FGFR2 mutations were validated by pyrosequencing of cSCC specimens. (a) EGFR g. 55249110 G > A (b) FGFR2 g. 123274818 T > A. Both (a,b) are reverse sequences.

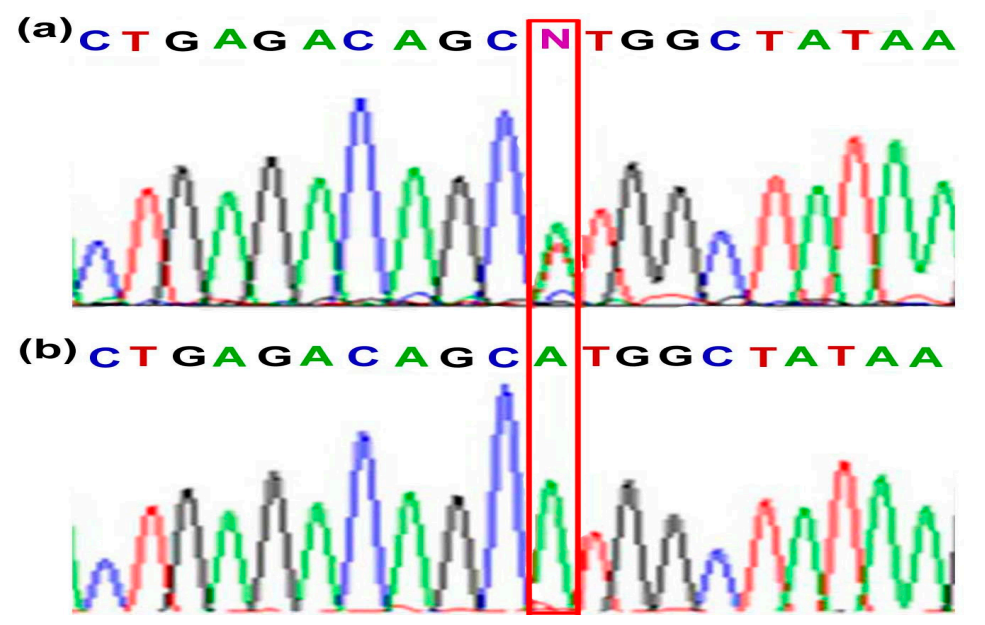

Figure 2. KDR mutation (g. $55972974 \mathrm{~T}>$ A) was validated by Sanger DNA sequencing of cSCC specimens: (a) heterozygous mutation (b) homozygous mutation.

The FGFR2 mutation existed at a higher frequency in older patients with cSCC $(p=0.032)$. There were no statistically significant differences in gender, location, histopathological differentiation and metastasis for KDR, FGFR2 and EGFR mutations. Among the high-risk cSCCs, KDR, FGFR2, and EGFR mutations were detected in $72 \%(p=0.028), 59 \%(p=0.001)$, and $57 \%(p<0.001)$ of high-risk CSCC, respectively (Table 4). According to the above results, the KDR g. $55972974 \mathrm{~T}>$ A occurred with the highest proportion. Although the FGFR2 and EGFR mutant rates are low, we consider that these mutations play some role in the tumors of older and high-risk CSCC patients. Additionally, the HNF1A mutation is most likely a sequencing artifact from the AmpliSeq Cancer HotSpot panel, as this variant is located at the end of the amplicon and is present at low frequency. 
Table 4. Target genes (KDR, FGFR2, EGFR) expressions in cSCC specimens ( $n=67)$.

\begin{tabular}{|c|c|c|c|c|c|c|c|c|c|c|}
\hline Characteristics & No. of Patients & & KDR & & & FGFR2 & & & EGFR & \\
\hline Age & Total & $\begin{array}{c}\text { Positive } \\
n\end{array}$ & $\begin{array}{c}\text { Negative } \\
n\end{array}$ & $\begin{array}{c}p \text {-value } \\
0.200\end{array}$ & $\begin{array}{c}\text { Positive } \\
n\end{array}$ & $\begin{array}{c}\text { Negative } \\
n\end{array}$ & $\begin{array}{c}p \text {-value } \\
0.032 *\end{array}$ & $\begin{array}{c}\text { Positive } \\
n\end{array}$ & $\begin{array}{c}\text { Negative } \\
n\end{array}$ & $\begin{array}{c}p \text {-value } \\
0.174\end{array}$ \\
\hline$<65$ & 16 & 12 & 4 & & 3 & 13 & & 3 & 13 & \\
\hline$\geqq 65$ & 51 & 29 & 22 & & 25 & 26 & & 19 & 32 & \\
\hline$\overline{\text { Sex }}$ & & & & 0.385 & & & 0.154 & & & 0.806 \\
\hline Male & 38 & 25 & 13 & & 13 & 25 & & 12 & 26 & \\
\hline Female & 29 & 16 & 13 & & 15 & 14 & & 10 & 19 & \\
\hline Location & & & & 0.721 & & & 0.080 & & & 0.241 \\
\hline Sunexposure & 42 & 25 & 17 & & 21 & 21 & & 16 & 26 & \\
\hline Non-sunarea & 25 & 16 & 9 & & 7 & 18 & & 6 & 19 & \\
\hline Differentiation & & & & 0.963 & & & 0.751 & & & 0.268 \\
\hline Poor & 19 & 12 & 7 & & 11 & 8 & & 8 & 11 & \\
\hline Moderate & 39 & 23 & 16 & & 11 & 28 & & 12 & 27 & \\
\hline Well & 9 & 6 & 3 & & 6 & 3 & & 2 & 7 & \\
\hline Recurrence & & & & 0.820 & & & 0.096 & & & $0.001^{*}$ \\
\hline No & 60 & 37 & 23 & & 23 & 37 & & 16 & 44 & \\
\hline Yes & 7 & 4 & 3 & & 5 & 2 & & 6 & 1 & \\
\hline Metastasis & & & & 0.845 & & & 0.379 & & & 0.985 \\
\hline No & 64 & 39 & 25 & & 26 & 38 & & 21 & 43 & \\
\hline Yes & 3 & 2 & 1 & & 2 & 1 & & 1 & 2 & \\
\hline Risk & & & & $0.028 *$ & & & $0.001 *$ & & & $<0.001$ * \\
\hline Low & 30 & 14 & 16 & & 6 & 24 & & 1 & 29 & \\
\hline High & 37 & 27 & 10 & & 22 & 15 & & 21 & 16 & \\
\hline
\end{tabular}

* The difference was considered significant when $p<0.05$. 


\section{Discussion}

The Ion Torrent Personal Genome Machine (Ion PGM) is a high-throughput DNA sequencing breakthrough, with applications beyond the conventional genomic sequencing which originally spurred its development $[15,19,20]$. This next generation sequencing technology provides rapid methods for genome-wide characterization and profiling of mRNAs, transcription factor regions, chromatin structure, metagenomics, and microbiology [15,19,21-23]. Ion PGM is unlike other conventional next-generation sequencing systems, which use dyes to label nucleotides and must be optically read via fluorescence imaging $[17,24]$. Ion PGM detects electrical signals directly on a semiconductor chip and reads nucleotides by sensing the $\mathrm{pH}$ value variation during complementary strand synthesis $[17,24]$. Whereas most sequencing techniques available nowadays take a week to process DNA samples, the Ion PGM analyzes sequences in a matter of hours $[17,18]$. It has surpassed traditional approaches in terms of economy, speed, and accuracy and offers comprehensive genetic information [15,19]. With shortened sequencing time, $99 \%$ accuracy $[17,24]$, and decreased experiment costs, sequencing has become affordable for more labs and researchers, resulting in an ever-increasing array of applications [20,24].

Skin cancers involve individualized genetic etiologies with somatic alterations that underlie mosaicism $[13,21,25,26]$. In the past years, several genes have been considered for association with cSCCs, but genes scattered within genomes with low prevalence are difficult to detect by traditional molecular methods $[13,27,28]$. Deep sequencing by next generation techniques can now probe heavily mutagenized genomes with large numbers of low-frequency mutations characteristic of skin cancers [13]. To the best of our knowledge, this study is the first use of Ion PGM to reveal gene mutations in high-risk cSCCs. High-risk CSCCs are characterized by tumor size $>2.0 \mathrm{~cm}$, high histological grade and localization on the ear or lip, deep and perineural invasion, recurrence, immunosuppression, and arsenic toxicity, usually with additional unfavorable prognoses and poor outcome [1,4,5,29-31]. Scientists suggest that highly mutagenized skin cancers may stimulate additional oncogenic pathways, such that combination strategies in targeted therapies may be required [13,32,33]. Early detection and development of target therapies for high-risk cSCC are imperative. Clarifying the genetic prospect of CSCC, especially the targets which have been generally sparse, would facilitate the development of targeted therapies for cSCC [9,32].

The KDR gene encodes VEGFR-2, a receptor tyrosine kinase overexpressed in a variety of solid tumors [34]. KDR also is an important factor in tumor progression and development due to its pro-angiogenic effects [35]. Previous studies indicated that the KDR g. $55972974 \mathrm{~T}>\mathrm{A}$ (p.Q472H) mutant had increased VEGFR-2 protein phosphorylation and was associated with increased microvessel density (MVD) in non-small cell lung cancer (NSCLC) tumor specimens [36]. KDR p.Q472H was identified in 7/10 lung adenocarcinomas and 1/1 mixed NSCLC/SCLC [34]. The KDR p.Q472H variant also appears to play a role in melanoma progression [37]. In addition, the mutation KDR p.Q472H also was found in Hepatic carcinosarcoma [38]. Therefore, KDR p.Q472H is a common variant in various tumors. Our data also implicates the $K D R$ p.Q472H variant in CSCC progression. This has not been reported before and suggests that further functional studies are warranted.

\section{Materials and Methods}

\subsection{Sample Collection}

Sixty-seven Asian samples with a diagnosis of squamous cell carcinoma of the skin were obtained from the dermatological and pathologic files and tumor registry from the Department of Pathology, Chung Shan Medical University Hospital, Taiwan (2002-2012). Formalin-fixed paraffin-embedded (FFPE) tissues of cSCC were obtained from the Departments of Dermatology and Pathology, Chung Shan Medical University Hospital, Taiwan. All histological sections were reviewed and the diagnoses were confirmed by the dermatologist and pathologist. Clinical information was extracted 
from medical records (Table 1). The study was approved by the Chung Shan Medical University Hospital (IRB No. CS12159) institutional review board. All tumors had been previously analyzed for next-generation sequencing and status.

\subsection{Genomic DNA Purification and Quantification}

Genomic DNA was extracted from tissues after enrichment for neoplastic cellularity, using manual microdissecion, and then processed with High Pure PCR Template Preparation Kit (Indianapolis, IN, USA). Quantitation of DNA was done using a Nanodrop 1000 spectrophotometer (Thermo Scientific Nanodrop Technologies, Wilmington, NC, USA).

\subsection{Ion Torrent Personal Genome Machine}

Ten nanograms of DNA was used for multiplex PCR of a panel covering 739 mutations in 46 cancer-related genes (Ion AmpliSeq Cancer Panel, Life Technologies). Library construction of the amplicons and subsequent enrichment of the sequencing beads were performed according to the manufacturer's protocol. While the sequencing run, the sample cSCC 1 had a coverage 2356 with 472,908 reads, and the sample cSCC 2 had a coverage 2374 with 482,928 reads. Sequencing was done on the 314 chip using the Ion Torrent Personal Genome Machine (Life Technologies) as per the manufacturer's protocol. Data analysis, including alignment to the hg19 human reference genome and base calling, was done using built-in software v2.2.

\subsection{Sequencing}

DNA extracted from the microdissected fresh-frozen skin cancers, pre-skin cancers and normal epidermis was subjected to whole genome amplification using Repli G (Qiagen, Germantown, OH, USA) and used in PCR as a template for specific primer sets (Figure 3) designed to amplify the target genes. DNA extracted from skin cancers was also amplified in PCR without undergoing prior whole genome amplification. PCR products were purified using ExoSap and used directly in Sanger sequencing with BigDye v3.1 and the Applied Biosystems 3730 sequencer for KDR and in pyrosequencing with the PyroMark sequencer for EGFR and FGFR2.

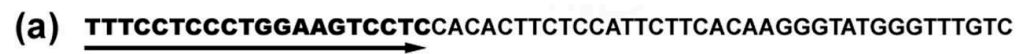

PCR primer

ACTGAGACAGC [ T/A ] TGGCTATAAGAAAGAGATAACAGCGCATATTATGATTTAAT

TTTTCTTTAATTAGAGTCAAGAGTAAGGAAAGATTCAGACTTTGGTTATTCTGTTCTT

AGAAATAACTTCCAACGCAGCC

Sequencing primer

PCR primer

(b) TGGGCATCTGCCTCACCTCCACCGTGCAGCTCATCACGCAGCTCATGCCCTTCGGCTGC

PCR primer- Biotin

СTCCTGGACTATGTCC [ G/A ] GGAACACAAAGACAATATTGGCTCCCATGACСTGCT

Sequencing primer

PCR primer

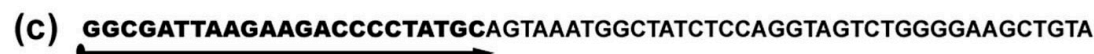

PCR primer- Biotin

ATCTCC [ T/A ] TTTCTCTTCCAGgCGCTAGATTGCAGATCACAGGAGgAGgAACAGATAA

Sequencing primer

GCAGGCCATAGAGTTAGCACACCAGACTGACGCATCATAGCACAACCAAAGGAACCAA

PCR primer

Figure 3. Specific primers for KDR, EGFR, and FGFR2 were used in this study: (a) primers for KDR mutation; (b) primers for mutation variant; (c) primers for FGFR2 mutation. 


\subsection{Statistical Analysis}

All experiments were performed and presented as means \pm SD. Statistical analyses were performed using one-way analysis of variance (ANOVA) followed by Tukey's post-hoc test (SPSS 17.0 software) to determine significant differences among the groups. The difference was considered significant when $p<0.05$.

\section{Conclusions}

In conclusion, we identified gene mutations in CSCC using personalized Ion Torrent technology. Furthermore, KDR, FGFR2, and EGFR gene mutations were found in high-risk cSCC, suggesting that these mutations could be potential therapeutic targets for CSCC treatment.

Acknowledgments: This work was supported by grants CSH-2013-C-018 and CSH-2014-C-023 from Chung Shan Medical University Hospital, Taiwan, and grant MOST 104-2311-B-040-001 from the Ministry of Science and Technology, Taiwan.

Author Contributions: Designed and conceived the experiments: Y.-P.H. and J.-J.Y. Performed the experiments: J. C.-C. and Y.-P.H. Interpreted and analyzed the data: C.-T.L., Y.-P.H. and J.-J.Y. Contributed materials: Y.-P.H., and W.-R.C. Drafted the manuscript: Y.-P.H., C.-T.L. and J.-J.Y. Critically revised the manuscript for important intellectual content: J.-J.Y.

Conflicts of Interest: The authors declare no conflict of interest.

\section{References}

1. Navarrete-Dechent, C.; Veness, M.J.; Droppelmann, N.; Uribe, P. High-risk cutaneous squamous cell carcinoma and the emerging role of sentinel lymph node biopsy: A literature review. J. Am. Acad. Dermatol. 2015, 73, 127-137. [CrossRef] [PubMed]

2. Kallini, J.R.; Hamed, N.; Khachemoune, A. Squamous cell carcinoma of the skin: Epidemiology, classification, management, and novel trends. Int. J. Dermatol. 2015, 54, 130-140. [CrossRef] [PubMed]

3. Azzimonti, B.; Zavattaro, E.; Provasi, M.; Vidali, M.; Conca, A.; Catalano, E.; Rimondini, L.; Colombo, E.; Valente, G. Intense Foxp $3^{+} \mathrm{CD} 25^{+}$regulatory T-cell infiltration is associated with high-grade cutaneous squamous cell carcinoma and counterbalanced by $\mathrm{CD} 8^{+} / \mathrm{Foxp}^{+} \mathrm{CD} 25^{+}$ratio. Br. J. Dermatol. 2015, 172, 64-73. [CrossRef] [PubMed]

4. Stratigos, A.; Garbe, C.; Lebbe, C.; Malvehy, J.; del Marmol, V.; Pehamberger, H.; Peris, K.; Becker, J.C.; Zalaudek, I.; Saiag, P.; et al. Diagnosis and treatment of invasive squamous cell carcinoma of the skin: European consensus-based interdisciplinary guideline. Eur. J. Cancer 2015, 51, 1989-2007. [CrossRef] [PubMed]

5. Brougham, N.D.; Tan, S.T. The incidence and risk factors of metastasis for cutaneous squamous cell carcinoma-Implications on the T-classification system. J. Surg. Oncol. 2014, 110, 876-882. [CrossRef]

6. Martorell-Calatayud, A.; Sanmartin Jimenez, O.; Cruz Mojarrieta, J.; Guillen Barona, C. Cutaneous squamous cell carcinoma: Defining the high-risk variant. Actas Dermo-Sifiliogr. 2013, 104, 367-379. [CrossRef]

7. Schmults, C.D.; Karia, P.S.; Carter, J.B.; Han, J.; Qureshi, A.A. Factors predictive of recurrence and death from cutaneous squamous cell carcinoma: A 10-year, single-institution cohort study. JAMA Dermatol. 2013, 149, 541-547. [CrossRef]

8. Nolan, R.C.; Chan, M.T.; Heenan, P.J. A clinicopathologic review of lethal nonmelanoma skin cancers in Western Australia. J. Am. Acad. Dermatol. 2005, 52, 101-108. [CrossRef] [PubMed]

9. Schwaederle, M.; Elkin, S.K.; Tomson, B.N.; Carter, J.L.; Kurzrock, R. Squamousness: Next-generation sequencing reveals shared molecular features across squamous tumor types. Cell Cycle 2015, 14, 2355-2361. [CrossRef] [PubMed]

10. Hertzler-Schaefer, K.; Mathew, G.; Somani, A.K.; Tholpady, S.; Kadakia, M.P.; Chen, Y.; Spandau, D.F.; Zhang, X. Pten loss induces autocrine FGF signaling to promote skin tumorigenesis. Cell Rep. 2014, 6, 818-826. [CrossRef]

11. Ratushny, V.; Gober, M.D.; Hick, R.; Ridky, T.W.; Seykora, J.T. From keratinocyte to cancer: The pathogenesis and modeling of cutaneous squamous cell carcinoma. J. Clin. Investig. 2012, 122, 464-472. [CrossRef] [PubMed] 
12. Zalaudek, I.; Giacomel, J.; Schmid, K.; Bondino, S.; Rosendahl, C.; Cavicchini, S.; Tourlaki, A.; Gasparini, S.; Bourne, P.; Keir, J.; et al. Dermatoscopy of facial actinic keratosis, intraepidermal carcinoma, and invasive squamous cell carcinoma: A progression model. J. Am. Acad. Dermatol. 2012, 66, 589-597. [CrossRef] [PubMed]

13. Cheng, J.B.; Cho, R.J. Genetics and epigenetics of the skin meet deep sequence. J. Investig. Dermatol. 2012, 132, 923-932. [CrossRef] [PubMed]

14. Futreal, P.A.; Coin, L.; Marshall, M.; Down, T.; Hubbard, T.; Wooster, R.; Rahman, N.; Stratton, M.R. A census of human cancer genes. Nat. Rev. Cancer 2004, 4, 177-183. [CrossRef] [PubMed]

15. Shendure, J.; Ji, H. Next-generation DNA sequencing. Nat. Biotechnol. 2008, 26, 1135-1145. [CrossRef] [PubMed]

16. Merriman, B.; Ion Torrent, R.; Team, D.; Rothberg, J.M. Progress in ion torrent semiconductor chip based sequencing. Electrophoresis 2012, 33, 3397-3417. [CrossRef] [PubMed]

17. Katsnelson, A. DNA Sequencing for the Masses. Available online: http://www.nature.com/news/2010/ 101214/full/news.2010.674.html (accessed on 3 January 2016).

18. Liu, L.; Li, Y.; Li, S.; Hu, N.; He, Y.; Pong, R.; Lin, D.; Lu, L.; Law, M. Comparison of next-generation sequencing systems. J. Biomed. Biotechnol. 2012, 2012, 251364. [CrossRef] [PubMed]

19. Ansorge, W.J. Next-generation DNA sequencing techniques. New Biotechnol. 2009, 25, 195-203. [CrossRef] [PubMed]

20. Cheng, C.S.; Rai, K.; Garber, M.; Hollinger, A.; Robbins, D.; Anderson, S.; Macbeth, A.; Tzou, A.; Carneiro, M.O.; Raychowdhury, R.; et al. Semiconductor-based DNA sequencing of histone modification states. Nat. Commun. 2013, 4, 2672. [CrossRef] [PubMed]

21. Maruthappu, T.; Scott, C.A.; Kelsell, D.P. Discovery in genetic skin disease: The impact of high throughput genetic technologies. Genes 2014, 5, 615-634. [CrossRef] [PubMed]

22. Lin, M.T.; Mosier, S.L.; Thiess, M.; Beierl, K.F.; Debeljak, M.; Tseng, L.H.; Chen, G.; Yegnasubramanian, S.; Ho, H.; Cope, L.; et al. Clinical validation of KRAS, BRAF, and EGFR mutation detection using next-generation sequencing. Am. J. Clin. Pathol. 2014, 141, 856-866. [CrossRef] [PubMed]

23. Rovigatti, U. Cancer modelling in the NGS era-Part I: Emerging technology and initial modelling. Crit. Rev. Oncol. Hematol. 2015, 96, 274-307. [CrossRef] [PubMed]

24. Wang, Y.; Wen, Z.; Shen, J.; Cheng, W.; Li, J.; Qin, X.; Ma, D.; Shi, Y. Comparison of the performance of ion torrent chips in noninvasive prenatal trisomy detection. J. Hum. Genet. 2014, 59, 393-396. [CrossRef] [PubMed]

25. Paniz Mondolfi, A.E.; Jour, G.; Johnson, M.; Reidy, J.; Cason, R.C.; Barkoh, B.A.; Benaim, G.; Singh, R.; Luthra, R. Primary cutaneous carcinosarcoma: Insights into its clonal origin and mutational pattern expression analysis through next-generation sequencing. Hum. Pathol. 2013, 44, 2853-2860. [CrossRef] [PubMed]

26. Martincorena, I.; Roshan, A.; Gerstung, M.; Ellis, P.; Van Loo, P.; McLaren, S.; Wedge, D.C.; Fullam, A.; Alexandrov, L.B.; Tubio, J.M.; et al. High burden and pervasive positive selection of somatic mutations in normal human skin. Science 2015, 348, 880-886. [CrossRef] [PubMed]

27. South, A.P.; Li, Q.; Uitto, J. Next-generation sequencing for mutation detection in heritable skin diseases: The paradigm of pseudoxanthoma elasticum. J. Investig. Dermatol. 2015, 135, 937-940. [CrossRef] [PubMed]

28. Stratton, M.R. Exploring the genomes of cancer cells: Progress and promise. Science 2011, 331, $1553-1558$. [CrossRef] [PubMed]

29. Wong, T.-W.; Tsao, S.; Lee, J.Y.-Y. In situ photoimmunotherapy is ineffective in treating deeply invasive squamous cell carcinoma. Dermatol. Sin. 2014, 32, 90-92. [CrossRef]

30. Alter, M.; Satzger, I.; Mattern, A.; Kapp, A.; Gutzmer, R. Treatment of advanced cutaneous squamous cell carcinomas with epidermal growth factor receptor inhibitors. Dermatology 2013, 227, 289-294. [CrossRef] [PubMed]

31. Schmitt, A.R.; Brewer, J.D.; Bordeaux, J.S.; Baum, C.L. Staging for cutaneous squamous cell carcinoma as a predictor of sentinel lymph node biopsy results: Meta-analysis of american joint committee on cancer criteria and a proposed alternative system. JAMA Dermatol. 2014, 150, 19-24. [CrossRef] [PubMed]

32. Al-Rohil, R.N.; Tarasen, A.J.; Carlson, J.A.; Wang, K.; Johnson, A.; Yelensky, R.; Lipson, D.; Elvin, J.A.; Vergilio, J.A.; Ali, S.M.; et al. Evaluation of 122 advanced-stage cutaneous squamous cell carcinomas by comprehensive genomic profiling opens the door for new routes to targeted therapies. Cancer 2016, 122, 249-257. [CrossRef] [PubMed] 
33. Mavropoulos, J.; Aldabagh, B.; Arron, S. Prospects for personalized targeted therapies for cutaneous squamous cell carcinoma. Semin. Cutan. Med. Surg. 2014, 33, 72-75. [CrossRef] [PubMed]

34. Mockus, S.M.; Potter, C.S.; Stafford, G.A.; Ananda, G.; Hinerfeld, D.; Tsongalis, G.I. Targeting KDR mutations in lung adenocarcinoma. In Proceedings of the 106th Annual Meeting of the American Association for Cancer Research, Philadelphia, PA, USA, 18-22 April 2015.

35. Ferrara, N.; Gerber, H.P.; LeCouter, J. The biology of VEGF and its receptors. Nat. Med. 2003, 9, 669-676. [CrossRef] [PubMed]

36. Glubb, D.M.; Cerri, E.; Giese, A.; Zhang, W.; Mirza, O.; Thompson, E.E.; Chen, P.; Das, S.; Jassem, J.; Rzyman, W.; et al. Novel functional germline variants in the vascular endothelial growth factor receptor 2 gene and their effect on gene expression and microvessel density in lung cancer. Clin. Cancer Res. 2011, 17, 5257-5267. [CrossRef] [PubMed]

37. Salgado, C.M.; Basu, D.; Nikiforova, M.; Hamilton, R.L.; Gehris, R.; Jakacki, R.; Panigrahy, A.; Yatsenko, S.; Reyes-Múgica, M. Amplification of mutated NRAS leading to congenital melanoma in neurocutaneous melanocytosis. Melanoma Res. 2015, 25, 453-460. [CrossRef] [PubMed]

38. Claudio Luchini, C.; Capelli, P.; Fassan, M.; Simbolo, M.; Mafficini, A.; Pedica, F.; Ruzzenente, A.; Guglielmi, A.; Corbo, V.; Scarpa, A. Next-Generation Histopathologic Diagnosis: A Lesson From a Hepatic Carcinosarcoma. J. Clin. Oncol. 2014, 32, e63-e66. [CrossRef] [PubMed]

(C) 2016 by the authors; licensee MDPI, Basel, Switzerland. This article is an open access article distributed under the terms and conditions of the Creative Commons Attribution (CC-BY) license (http://creativecommons.org/licenses/by/4.0/). 